\title{
Study on the Translation of Cultural-loaded Words in the Novels of Ethnic Minorities
}

\author{
Yulan Wang \\ Shandong Youth University of Political Science, Jinan, Shandong, 250000
}

Keywords: Cultural-loaded Words, Novels of Ethnic Minorities, English Translation

\begin{abstract}
China's minority culture has gradually moved to the world, and the demand for translation of ethnic folklore and culture has also increased. As we all know, culture, language and translation are closely related. Each language has rich cultural connotations, and language is culture. For this reason, when translating the texts of ethnic folklore and culture, a large number of national cultural load words will be encountered. This report is to study the classification and summary of the national cultural load words translation strategy after translating the Mongolian, Manchu and Ewenki national cultural texts.
\end{abstract}

\section{Introduction}

Culturally loaded words refer to words, phrases and idioms that mark specific vocabulary in a certain culture; national culturally loaded words are vocabulary with distinct national cultural characteristics, reflecting the history, culture and folk customs of a particular nation, and semantically The characteristics of proprietary or non-corresponding, that is, cultural color. Therefore, translation must use flexible and flexible means to accurately convey the cultural connotation of vocabulary.

For the translation of cultural texts, the process of translation is a simple conversion of linguistic symbols. It is also the blending of language and the integration of culture. The purpose of translation is to assimilate different cultures, but to transplant and blend them. Due to the huge cultural differences between the small languages, a large number of national cultural load vocabulary is difficult to find in the target language. Therefore, the summary of the national culture: load word translation strategy has positive significance for the dissemination and communication of different national cultures. .

\section{The problem of unification of culturally loaded word translation}

For the translation of culturally-loaded words, because the translators have different perspectives and different translation strategies, the same cultural load words currently have many different versions. This phenomenon exists objectively and is a normal phenomenon in translation. For example: comic dialogue, crosstalk; poetry the Immortal Poet, Immortal of Poems; poetry the sage of poems, poet sage; ritual Book of rites, The Records of Rites, Liji; Qingming Festival Qingming Festival, The Pure Brightness Day, Tomb Sweeping Day; dragon, Chinese dragon, Loong; five elements wuxing, five agents, five elements, five phases; Oracle boneinscriptions, jiaguwen; Yi Jing I Ching, Book Of Changes, Law of Change, The Classic of Changes; Tao Te, The Dao De Jing; Shiji, Historical Records, Records of the Grand Historian. However, the diversity of English translation of the same cultural load words is actually not conducive to the external spread of Chinese culture. The more the translations are, the more chaotic they are, which is likely to cause misunderstandings by foreign readers. In cross-cultural communication, China is a whole. If there is a big difference in the English translation of a certain word in China, there are multiple versions, then how can we be consistent? If more than one version is sent abroad, How can foreign readers not be confused?

Of course, the issue of the unification of the translation is not one step in place, and we cannot rush to seek success. We can walk step by step. We should first solve the translation problems of the 
most representative words in Chinese culture. First, the national cultural propaganda department will take the lead in selecting the most Chinese cultural vocabulary in each cultural field, such as collecting a total of 1,000, organizing domestic and foreign experts to negotiate translation, and then comprehensible and acceptable translation. The survey, based on a variety of factors, was finalized and compiled into a book as a model for Chinese cultural translation.

These representative culturally loaded words should be macroscopic, typical, and not very professional. For example, Confucius, Laozi, Sun Tzu's Art of War, Thirty-six, the Spring Festival, the Dragon Boat Festival, the four famous books and their translated names, four major inventions, Peking Opera, Feng Shui, Tai Chi, Taoism, cross talk, sketch, New Year's Eve, dumplings or dumplings, Oracle, Martial arts, cheongsam, Chinese characters, etc., these words are typical representatives of Chinese culture. At this point, the "Gourmet Translation Court - English Translation of Chinese Menu" compiled by the Beijing Foreign Affairs Office in 2008 is a good attempt. Second, it is possible to make the major publishers strictly control the translation of Chinese culture through administrative power, and must conform to the translation of the model. For example, the translation of the dragon, if the country is consistently translated into loong, and no longer use dragon or Chinese dragon to translate, presumably in a few years will reverse the world's misunderstanding of the Chinese dragon, this is the power of unity.

\section{Functional equivalence and naturalization}

The so-called functional equivalence is to consider the reflection effect of the reader, and requires the translator to not only achieve the equivalent of the translated language and the original language in the lexical sense, but also to make the semantics, style and style equal. In other words, the translation conveys both surface vocabulary information and deep cultural information. When translating the load words of national culture, the "rigid" translation will result in the lack of cultural information, affecting the integrity, authenticity and acceptability of the original cultural information. Therefore, when translating national cultural vocabulary, in addition to considering the literal meaning, it is also important to choose the appropriate expression. This is in line with the principle of naturalization proposed by Lawrence Venuti. The so-called naturalization refers to adopting a fluent style of writing, aiming at the target language or the target reader, and using the expressions of the target language readers to convey the content of the original text, thereby reducing the translation of the foreign language of the original language. In the translation of national cultural load words under the guidance of functional equivalence and naturalization principles, there are mainly two methods of translation:

When translating the texts of minority cultures, they will encounter a large number of culturally loaded words. Some can't find corresponding expressions in the cultural system, which leads to the vacancy of culturally loaded words. This part of the vocabulary is unique. If transliteration or literal translation is performed during translation, the target language reader cannot understand the meaning of the original expression, and sometimes even cause misunderstanding. At this time, it is inevitable to use the free translation method. Just as the semantic equivalence proposed by Yida and Venuti's emphasis on reducing the color of alienation, free translation means translating according to the original meaning of the original text, rather than a verbatim translation. It emphasizes a relatively independent translation culture system and a primitive cultural system. In this way, in the process of translation, the literal meaning of the original text cannot be retained. In order to facilitate the reader's understanding and achieve the purpose of cultural transmission, the image in the original text can be replaced with the image familiar to the reader.

Due to different historical and cultural developments, the national cultural load words are unique. Many vocabulary such as place names and institutions have gradually evolved and formed in the course of historical development. In translation, if only word-to-word translation is used, cultural communication cannot be achieved. Therefore, in order to accurately convey the original text information and the cultural information under the original text, it is often necessary to add translations to the translation, that is, according to the same thinking mode, language habits and expressions of English and Chinese, add some words or Sentences to more accurately express the 
meaning of the original text. Of course, the additional translation is arbitrarily increased, but it increases the part of the original text that has no meaning but has its meaning. In addition, there is a big difference in the habits of expression between Chinese and English. Chinese is important and English is reconciled. In some cases, if you use Chinese to translate English-to-word texts, it will be slightly dragged. Therefore, when translating texts with historical and cultural backgrounds, provincial translations are also used. The provincial translation method is a translation method corresponding to the translation method, that is, the words that do not conform to the target language thinking habits, language habits and expressions are deleted to avoid the cumbersome translation.

\section{Formal Equivalence and Alienation}

The so-called form equivalence emphasizes the form and content of the original text, and hopes to achieve the equivalence between the original text and the translated text, and to some extent reflect the linguistic features of the original vocabulary, grammar, and syntactic structure. It requires translators to consider textual correspondence more when translating, in order to be accurate. On the other hand, Lawrence also believes that alienation is quite important. The so-called alienation refers to the translation of the foreign language characteristics of the original language by removing the language specification of the target language to a certain extent, that is, "the translator tries to disturb the author as much as possible, and let the reader move closer to the author." Lawrence said, "Abolition is a clever cultural intervention in today's world affairs." As mentioned above, the national cultural load words are mainly divided into three categories, namely, material cultural words, conceptual cultural words and behavioral cultural words, which are unique to minority cultures. If they are naturalized, it is difficult to Vocabulary and culture are introduced to the target language readers.

The national cultural load words have distinctive characteristics. The names and place names unique to minority languages cannot be found in the translated language. In order to achieve literal fax, a transliteration method is needed. In some minority languages, such as Mongolian, there are many homonyms, which are difficult to distinguish and distinguish between the same characters. This brings certain difficulties to minority language information processing. When dealing with these text messages, the usual method is Latin transfer. Transliteration is a form of translation based on the pronunciation of the original language. Generally, the translation of the original language content is used to find similar pronunciation in the target language for alternative translation. It is most frequently used in the translation of national cultural load words. Translation of national cultural texts, national languages, and proprietary geographical names requires such processing.

Nida believes that the translation of the target reader's response to the translation is basically the same as the original reader's response to the original text, and the translation can be said to be successful. Nida also advocates that the information conveyed by the translation includes only the content of the thought and should also include the language form. The translator can't arbitrarily increase the thoughts that the original works, and the smaller ones can arbitrarily delete the original ideas. That is to say, in the translation, the translator should retain the original expression as much as possible, and use the literal translation method, that is, the translation method that maintains the original content and maintains the original form. It focuses on the accurate conveyance of the form and, if necessary, ignores certain implied elements of the original content. As Lawrence believes, the purpose of the alienation strategy is to consider the differences of national culture, preserve and reflect the characteristics of foreign nationalities and language styles, and preserve the exotic atmosphere for the target readers. Therefore, the use of literal translation may affect the transmission of cultural connotations, but it is the most authentic translation of national culture. In the translation of the national cultural load words, the enumeration and classification of things will use the literal translation method a lot. 


\section{Conclusion}

Some texts in the source language culture are common in texts with national cultural characteristics. They are "blank" or "vacancies" in the translated language, so in the process of translation, it is difficult to grasp the translation of the load words of national culture. . The process of translation is an interactive process of transmission and acceptance of cultural information. For translations, in order to achieve this effect, it is necessary to maintain the transmission of cultural information.

\section{Acknowledgements}

Fund Project: The paper is supported by Social Science Planning and Research Project of Shandong Province, and part of the research results of project named "A Study on the Translation of Cultural-loaded Words in the Novels of Ethnic Minorities”

Project Number: 18CWZJ56

\section{References}

[1] Yang Le, Zhou Chunxiang. Analysis of English Translation Methods of Traditional Chinese Medicine Based on Two Versions of Treatise on Febrile Diseases [J]. Shizhen Guo Guo Guo Yao, 2013, 24(8): 2037 -2039.

[2] Guo Shanshan. A number of English titles in the textbook "Treatise on Febrile Diseases" [J]. Chinese Journal of Integrated Traditional and Western Medicine, 2010, 30(9): 993 - 994.

[3] Lin Tingxiu, Sun Yan. Development and Thinking of English Translation of Treatise on Febrile Diseases [J]. Chinese Medicine Education, 2010, 29(3): 29 - 31.

[4] Liu Yanli, Yang Ziwei. Also talk about "naturalization" and "alienation" [J]. Chinese translation, 2002, 23(6): 20 - 24.

[5] Yao Xin, Sheng Jie. An Analysis of English Translation of Names of Traditional Chinese Medicine from the Perspective of Functional Equivalence Theory [J]. Medicine and Philosophy, 2012, 33(10): 72 - 74. 